\title{
Death Certificate
}

\section{AUTHOR}

Adrian M. Schnall

CORRESPONDENCE

DOI

a.schnall@att.net

10.20411/pai.v2i3.144

216-218-5788

\section{AFFILIATION}

Department of Medicine, Case Western Reserve School of Medicine, Cleveland, Ohio

How far back in the chain to go?

I'm penning in an entry

on the parchment of public record,

creating a statistic for the students of disease,

writing too the final word

on the last page of the book

for the bereaved.

So robust, barrel of a woman,

layered in corsets from another century.

Her heart went dead December first,

but Staphylococci started

seeding her veins three days before,

breeding in the purple sore

that showed its color Labor Day.

An ulcer on her bottom,

branded there by months of sitting

staring at air, still as a Stonehenge rock.

We lost her when her mind burned out in May.

Should I say dementia killed her?

Not enough space

for a dissertation

on causation and its subtleties.

I can't just call it stoppage 
of the clock-

that's one frame

of thousands

in a documentary.

I settle for "Septicemia, Staph."

The statisticians will be pleased, two different categories.

And there's her daughter's face, and her grandchildren at peace, remembering her as maimed

by an invading legion, forgetting

her forgetting

of their names. 